\title{
Prevalence and Pathology of Bovine Tuberculosis among Cattle Population Slaughtered in Abeokuta Abattoir
}

\author{
Mshelbwala, F. M ${ }^{1}$., Oladotun, O. O' ${ }^{1}$, Kadiri, A. K. F ${ }^{2}$., Abakpa, S. A. V ${ }^{3}$, Nyillah, E. L . \\ ${ }^{\prime}$ Department of Veterinary Pathology, College of Veterinary Medicine, Federal University \\ of Agriculture, Abeokuta \\ ${ }^{2}$ Department of Veterinary Medicine, Faculty of Veterinary Medicine, Ahmadu Bello \\ University, Zaria \\ ${ }^{3}$ Department of Veterinary Medicine, College of Veterinary Medicine, Federal University \\ of Agriculture, Abeokuta

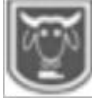 \\ ${ }^{4}$ Department of Veterinary Pathology, Faculty of Veterinary Medicine, \\ Ahmadu Bello University, Zaria \\ *Corresponding author: Tel. 08109064065 ; \\ Abstract
}

The prevalence of bovine tuberculosis among cattle population slaughtered in Lafenwa, Abeokuta, abattoir was determined and the pathology associated with the disease was described in the present study. The ages, sexes and total number of cattle slaughtered and examined was recorded over a period of six months (October, 2015 to March, 2016), out of which suspected cases of tuberculosis were sorted out. The prevalence of bovine tuberculosis was calculated as percentage of occurrence as overall, age and sex-specific; and gross lesions were described. Tissue samples of the lungs, liver, Intestine, lymph nodes were collected from the affected animals in two parts; one for Ziehl Nelson staining and the other was fixed in $10 \%$ buffered formalin for histopathology. Among the 25,875 cattle examined, an overall prevalence of $8.72 \%$ was recorded. Monthly prevalence varied from $5.28 \%$ in October to $11.33 \%$ in December, 2015. Sex-specific prevalence was higher infemales (89.94\%) than in males (1.0.06\%). Gross lesions observed were severe and diffused necrosis in the lung parenchyma with marked creamy caseous yellowish nodules of variables sizes in 100\% of the cases. In some cases, similar lesions were observed in the liver, intestine, heart, kidneys and lymph node. Histopathological lesions in the lung and extra-pulmonary organs were severe necrosis with calcified centers; and there were granulomatous inflammation. Ziehl Neelsen stain demonstrated reddish bacilli suggestive of Mycobacterium organisms. There was an increase in the cases of tuberculosis among cattle population slaughtered in Lafenwa abattoir when compared with those reported in previous studies.

Keywords: Cattle, Abattoir, histopathology, bovine tuberculosis

\section{Introduction}

Sustainable agricultural development is one of the main prerequisites for obtaining growth and stability of the economy of an agrarian nation like Nigeria, in which livestock production play an important role (Oluwafemi et al., 2001; Amanfu, 2006). They also provide great inputs to crop production as most farms in the developing world are too small to own or use a tractor, and the alternatives are animal power or human labour (Amanfu, 2006). Cattle are one of the major livestock produced in Nigeria, because of their high adaptation to different environmental conditions (Cadmus et al., 2004; Amanfu, 2006). However, cattle production in Nigeria is faced with many diseases challenges, among which Bovine tuberculosis takes a high place. Bovine tuberculosis is a chronic bacterial disease of 


\section{Prevalence and Pathology of Bovine Tuberculosis}

animals and humans mostly caused by Mycobacterium bovis (Smith et al., 2006) but can also be caused by other members of the Mycobacterium tuberculosis complex (MTbC) (Brosch et al., 2002). It has been reported that Mycobacterium tuberculosis as well as other members of the MTbC are causes of tuberculosis in cattle in Nigeria (Cadmus et al., 2006; Cadmus et al., 2010; Jenkins et al., 2011). Mycobacterium bovis is an infectious agent that can also cause tuberculosis in other domesticated animals and certain free or captive wildlife species (OIE, 2009). It is usually characterized by formation of granulomas known as tubercles (Shitaye et al., 2007). Although commonly defined as a chronic debilitating disease, bovine tuberculosis can occasionally assume a more progressive course. It can affect any tissue of the body, but lesions are most frequently observed in the lymph nodes (particularly of head and thorax), lungs, intestines, liver, spleen, pleura and peritoneum (OIE, 2009). Other members of the $M$. tuberculosis complex, that were previously considered to be $M$. bovis, have been accepted as new species despite identical 16s RNA sequences and over $99.9 \%$ identity of their genome sequences. These include $M$. caprae (Aranaz et al., 2003) (in some countries considered to be a primary pathogen of goats) and M. pinnipedii (Cousins, 2001), a pathogen of fur seals and sea lions. These two new species are known to be zoonotic. In central Europe, M. caprae has been identified as a common cause of bovine tuberculosis (Prodinger et al., 2005). Disease caused by $M$. caprae is not considered to be substantially different from that caused by $M$. bovis and the same tests can be used for its diagnosis (OIE, 2009). Consumption of unpasteurized milk is the most important route of contracting the disease in developing countries (Ayanwale, 1984; Shehu, 1988; Abubakar, 2007; Wilkinset al., 2008). The human cases of tuberculosis associated with Mycobacterium bovis infection, both pulmonary and extra pulmonary has been on the increase in Nigeria (Idigbe et al., 1986; Cadmus et al., 2004; Abubakar, 2007). Clinical signs vary when they are present; lung involvement may be manifested by dyspnea, pneumonia, cough, which can be induced by temperature changes or applying manual pressure on the trachea. Lymph nodes (of the head and neck) are often affected and may rupture and drain (OIE, 2009). Tuberculosis can be difficult to diagnose based on the clinical signs. In developed countries, few infections become symptomatic; most are diagnosed by routine testing including serology, or found at the slaughterhouse (CFSPH, 2007). Gross lesions of tubercles (De Lisle et al., 2001) and histopathological lesions of granulomatous reaction are highly diagnostic for tuberculosis (Shitaye et al., 2007; Marais et al., 2008). Ziehl Neelsen stain has also been used for the diagnosis of bovine tuberculosis, with highly suggestive result (Marais et al., 2008), but confirmation can be done by isolation and identification of the Mycobacterium organism (Sam et al., 2011). Most of the cattle presented for slaughter in Abeokuta abattoirs are brought from different places such as the far northern Nigeria, Niger Republic, Chad, Benin Republic and other African countries without any clinical history (Cadmus et al., 2004). While Awosile et al. (2012) reported a prevalence of $1.78 \%$ in Lafenwa abattoir, Abeokuta, the gross and histopathological lesions were not described; and there is no recent work to ascertain the situation of tuberculosis among cattle slaughtered in Abeokuta, Ogun State, Nigeria. 


\section{Materials and methods \\ Study area}

The study was conducted in Abeokuta, Ogun State. The state is bounded by Lagos, Osun and Oyo states. The vegetation of south west Nigeria is made up of tropical rain forest (Ogunsesan et al., 2003). Nigeria has a humid climate with average annual temperature and rainfall of $29-39^{\circ} \mathrm{C}$ and $2000 \mathrm{~mm} / \mathrm{hg}$ respectively with the relative humidity of 41-67\% (Omogbai, 2010; Olorunfemi and Fasimirin, 2011). The administrative capital of Ogun State is Abeokuta where samples were collected from cattle presented for slaughter at the abattoirs and sent to the Department of Veterinary Pathology, Federal University of Agriculture, Abeokuta for analysis.

Population characteristics of cattle slaughtered in Lafenwa, Abeukuta abattoir

Cattle presented in Abeokuta Abattoir for slaughter were examined to determine their ages and sexes for a period of six months (October to March, 2016). The total number of cattle slaughtered in every month of examination was retrieved from the record book of the abattoir.

\section{Prevalence of tuberculosis}

Suspected cases of tuberculosis were sorted out from the total number of cattle slaughtered according to the month of examination. The prevalence of bovine tuberculosis was determined by calculating the percentage of occurrence of tuberculosis among the cattle population slaughtered in the Lafenwa, Abeokuta abattoir; as overall, age-specific and sexspecific.

\section{Gross Pathology}

The carcasses of the cattle were examined for pathological lesions. Gross lesions of suspected cases of bovine tuberculosis encountered were described. Tissue samples of the lungs (suspected pulmonary tuberculosis) and liver, Intestine, lymph nodes (suspected miliary tuberculosis) making a total of 36 , were collected from the affected animals in two parts; one for Ziehl Nelson staining and the other was fixed in $10 \%$ buffered formalin for histopathology.

\section{Histopathology}

The tissue samples of lung, lymph node, liver and intestine that were fixed in $10 \%$ buffered formalin were processed and cut into $6 \mu \mathrm{m}$ thick with rotary microtone machine and stained with Haematoxylin and Eosin stains as described by Awvioro (2002). The stained tissues were examined with light microscope for histopathological lesions.

\section{Acidfast stains (Ziehl Neelsen)}

Procedure for acidfast staining

Ziehl Neelsen staining was carried out to determine the acid fast organisms, according to the method described by various workers (Morello et al., 2006; Newton et al., 2008; Robert, 2009). Smears from suspected tissue samples were made on clean glass slides and air dried for 10 minutes. The smears were floaded with carbol fuchsin (primary stain) and a flame from spirit lamp was held beneath the slides containing the smear until steam appeared over it. The slides were allowed to cool for 5 minutes and the smear were rinsed with tap water. The smears were flooded with $20 \%$ sulphuric acid and allowed to stay for 1 minute in order to decolourize the carbol fuchsin stain, then counter stained with methylene blue and allowed to stay for 1 minute. The smears were then rinsed with tap water; air dried, and viewed with light microscope under $\mathrm{x} 100$ oil immersion lens.

\section{Results}

The total number of cattle slaughtered in Lafenwa abattoir, Abeokuta during the six months study was 25,875 . The population of cattle slaughtered in Lafenwa abattoir, Abeokuta was mainly female (89.94\%), 


\section{Prevalence and Pathology of Bovine Tuberculosis}

(Table 1). The overall prevalence of tuberculosis in cattle slaughtered in Lafenwa abattoir, Abeokuta was $8.72 \%$. Monthly prevalence varied from $5.28 \%$ in October to $11.33 \%$ in December (Table 1).
Age-specific prevalence was higher among adult cattle $(7.51 \%)$ while lower prevalence was recorded among young cattle $(1.21 \%)$ (Table 2).

Table 1: Overall prevalence of tuberculosis among cattle population slaughtered in Lafenwa abattoi Abeokuta; between October, 2015 and March, 2016

\begin{tabular}{llll}
\hline Month & Number of animals slaughtered & Number of animals with lesions & Prevalence (\%) \\
\hline October, 2015 & 4449 & 235 & 5.28 \\
November, 2015 & 4484 & 438 & 7.09 \\
December, 2015 & 4582 & 519 & 11.33 \\
January, 2016 & 3933 & 378 & 9.61 \\
February, 2016 & 4175 & 353 & 8.46 \\
March, 2016 & 4252 & 334 & 7.86 \\
Overall & 25875 & 2257 & 8.72 \\
\hline
\end{tabular}

Table 2: Age-specific prevalence of tuberculosis among cattle population slaughtered in Lafenwa abattoir

\begin{tabular}{llll}
\hline Age & Number of cattle slaughtered & Number of cattle with tuberculosis & Prevalence (\%) \\
Adult & 23271 & 1943 & 7.51 \\
Young & 2604 & 314 & 1.21 \\
Overall & 25875 & 2257 & 8.72 \\
\hline
\end{tabular}

Sex-specific prevalence of tuberculosis 2015 to March, 2016 was higher in females among cattle population slaughtered in (89.94\%)than in males $(1.0 .06 \%)$ (Table 3$)$.

Lafenwa abattoir, Abeokuta from October,

Table 3: Sex specific population characteristic of cattle slaughtered between October 2015 and March 2016 in Lafenwa abattoir, Abeokuta,between October, 2015 to March, 2016.

\begin{tabular}{llll}
\hline Sex & No. Of cattle slaughtered & Number of cattle with tuberculosis & Percentage (\%) \\
Male & 8604 & 10.06 \\
Female & 17271 & 89.94 \\
Overall & 25875 & 100 \\
\hline
\end{tabular}

\section{Gross Pathology}

Gross lesions observed were severe and diffused necrosis of the lung parenchyma with marked creamy caseous yellowish nodules of variables sizes in $100 \%$ of the cases. The nodules were observed on the pleural surfaces and deep in the lung parenchyma.

In some cases, extrapulmonary lesions were observed in the liver, intestine, heart, and the kidney (miliary tuberculosis) (Figures 1 and 2).

\section{Histopathology}

Microscopic lesions were severe, diffused and extensive necrosis of the lung parenchyma, surrounded by inflammatory cells, mainly macrophages and giant cells. The lesions were surrounded by fibrous connective tissue, with infiltration of lymphocytes and plasma cells in $100 \%$ of the cases examined. The central areas of necrosis were calcified in $70 \%$ of the cases, giving it the characteristic granuloma lesion (Figures 3 and 4).

\section{Ziehl Neelsen stain}

All the 36 tissue samples of lung, lymph node liver and intestine stained with Ziehl Neelsen stain demonstrated reddish bacilli suggestive of Mycobacterium species (Figure 5). 
Mshelbwala, Oladotun, Kadiri, Abakpa, Nyillah

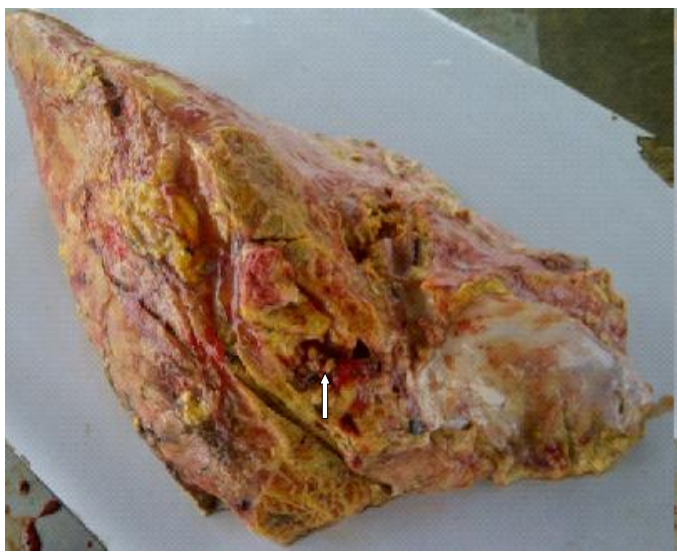

Figure 1: Photograph of the lung of a cow slaughtered in Lafenwa abattoir showing creamy yellowish nodules in the pleural surfaces and in the cut surface of the parenchyma (arrow).

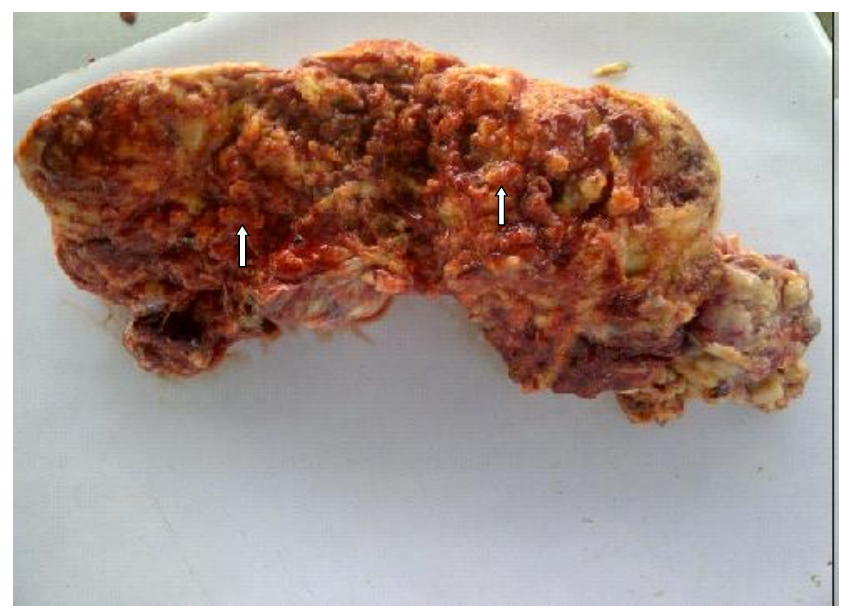

Figure 2: Photograph of the lung of a cow slaughtered in Lafenwa abattoir showing creamy yellowish nodules in the pleural surfaces and in the cut surface of the parenchyma (arrows).

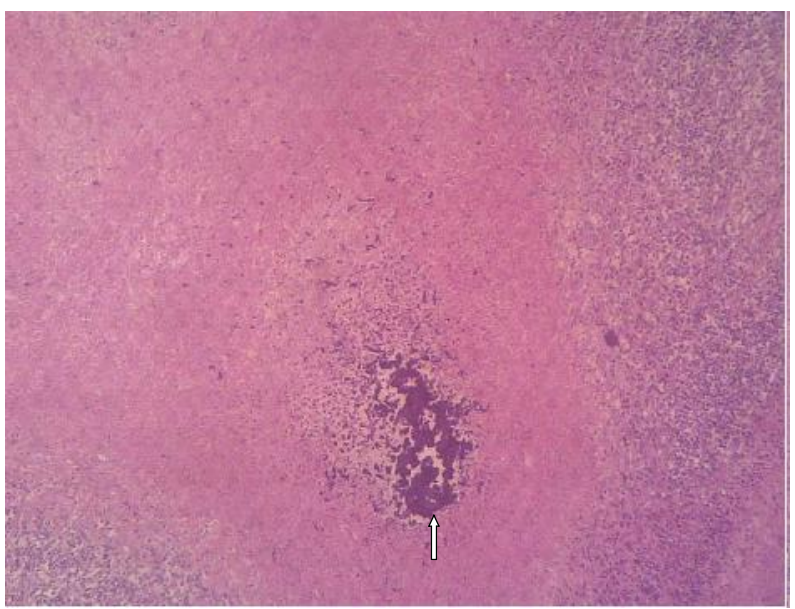

Figure 3: Section of the lung of a cow slaughtered in Lafenwa abattoir, Abeokuta showing severe necrosis of lung parenchyma with calcified center (arrow) $(x 100 ; \mathrm{H} \& \mathrm{E})$ 


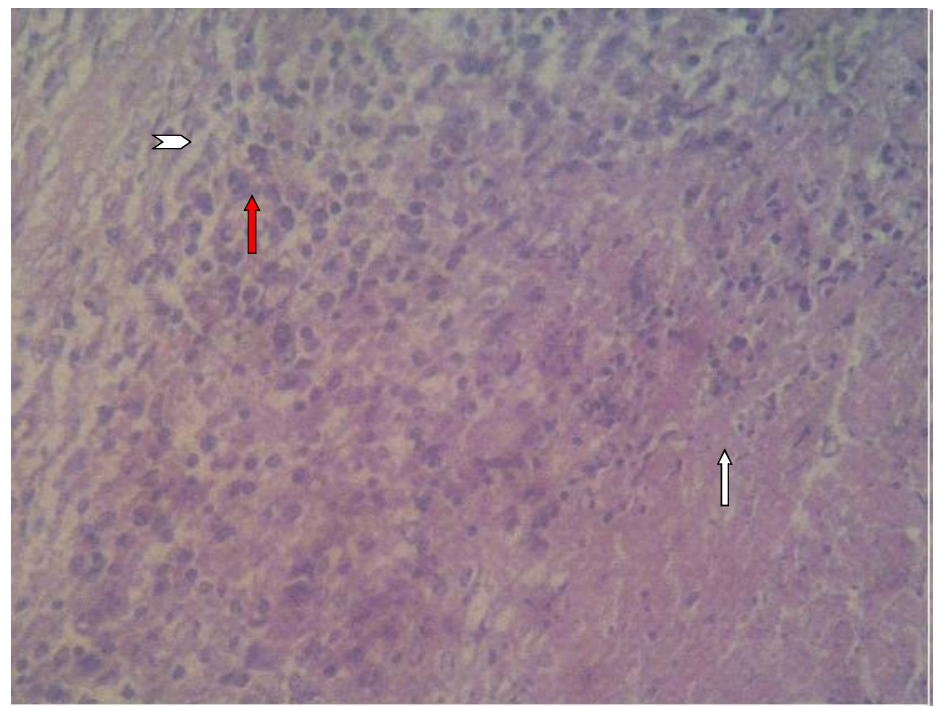
Figure 4: Section of the lung of a cow slaughtered in Lafenwa abattoir, Abeokuta, showing severe
necrosis of lung parenchyma (white arrow), infiltration by macrophages, giant cells and lymphocytes (red arrow) with fibrous connective tissues (arrow head) (x400; H\&E)

Figure 5: Photomicrograph of a stained tissue smear made from the lung of a cow slaughtered at Lafenwa abattoir, Abeokuta, showing acid fast bacilli (arrow) (x1000; Ziehl Neelsen stain)

\section{Discussion}

The cattle population slaughtered at Lafenwa abattoir, Abeokuta between October and March, 2016 were mostly adult cows ( $89.94 \%)$. These could be cows that are thought to have spent their productive live span. However, massive culling of adult cows could have deleterious implications on the economy of Nigeria at large, because of the milk loss, calves lost (in pregnant animals), hides and skin loss and other prospective losses, which could have been of economic benefit had the animals been kept alive and in the production system. The action of culling adult cows could also account for the protein malnutrition in some African countries and a possible constraint to future livestock populations in the continent (Nwakpu and Osakwe 2007; Ademola 2010; Cadmus and Adesokan, 2010). The act of maternal slaughter (in most cases) also tends to frustrate the efforts of breeders and geneticists as it poses the risk of widening the gap of animal protein requirements by meat consumers (Khan and Khan 1989). Poor financial condition of the farmers and ignorance of the pregnancy state of the 


\section{Mshelbwala, Oladotun, Kadiri, Abakpa, Nyillah}

animals have been reported to be the reasons for culling and slaughtering pregnant livestock (Sanusi et al., 2006; Muhammad et al., 2009).

The overall prevalence of tuberculosis in Lafenwa abattoir, Abeokuta increased from the $1.78 \%$ reported by Awosile et al. (2012) to $8.72 \%$ (between October, 2015 and March, 2016). This implies that there is continuous exposure of apparently healthy animal flocks and even humans because of the zoonotic importance of the disease. The increase in the prevalence of tuberculosis agreed with the report of Amanfu (2006) that the situation is worsened and the control programme in farm animals has not been effective and this poses a serious health hazard to the human population. Nwanta et al. (2011) reported the occurrence of tuberculosis in cattle and human population in Enugu, Ngeria. The occurrence of the disease increased during the dry season (Nov-Feb) with notable increase in December, 2015 which agreed with the report of Auda (2011) who attributed the increase in December to the extreme dryness of the weather which aids aerosolization of the organisms and easy transmission through dust particles.

Ejeh et al. (2014) estimated the economic loss to bovine tuberculosis in Makurdi with prevalence of $0.9 \%$ in 2008 and $4.04 \%$ in 2012 at $\$ 2.91 \times 10^{6}$ and $\$ 3.56 \times 10^{5}$. Kwaghe et al. (2015) also estimated the economic loss to bovine tuberculosis in Maiduguri with a prevalence of $8.08 \%$ in females and $1.02 \%$ in males respectively to be N4,841,879.2, $\$ 349,580,199.89$ and a total of $\mathrm{N} 349,580,199.89$ which indicated that bovine tuberculosis in Nigeria is not just a threat to the economy of the livestock industry but also to food security, food safety and the health of the public.

The gross lesions of severe and diffuse areas of necrosis with yellowish creamy and caseous nodules which were seen in the lung, lymp node, liver, kidney, heart and intestine are consistent findings in bovine tuberculosis (De Lisle et al., 2001). Mycobacterium bovis is a facultative intracellular pathogen known to cause granulomatous inflammation in the lung, liver and other organs (Kubica et al., 2006). The histopathological lesions of necrotic and calcified center surrounded by numerous macrophages, fibrous connective tissues and giant cells are also consistent with bovine tuberculosis (Nair et al., 2006), and correlated well with the gross lesion.

Ziehl Neelsen stain has been used in the diagnosis of bovine tuberculosis (Newton $e t$ $a l ., 2008)$. The stain was found to be highly sensitive in detecting Mycobacterium bovis in tissues and should be applied where isolation and identification is not possible.

\section{Conclusion}

In conclusion, most of the cattle slaughtered in Lafenwa abattoir, Abeokuta abattoir were female $(89.94 \%)$ and this pose serious economic loss. The overall prevalence of $8.72 \%$ of bovine tuberculosis in Lafenwa abattoir, Abeokuta recorded in this study was higher than the ones reported earlier. Gross lesions of bovine tuberculosis correlated well with the microscopic lesions which were diagnostic for bovine tuberculosis; and Ziehl Neelsen stain was highly sensitive in the diagnosis of bovine tuberculosis.

\section{References}

Abubakar, I. A. 2007. Molecular epidemiology of human and bovine tuberculosis in the Federal Capital Territory and Kaduna state.Ph .D Thesis, Plymouth University, U.K.

Ademola, A. 2010. Incidence of fetal wastage in cattle slaughtered at the Oko-Oba Abattoir and Lairage, Agege, Lagos, Nigeria. Journal of 


\section{Prevalence and Pathology of Bovine Tuberculosis}

Veterinary Resources, 3(3): 54-57.

Amanfu, W. 2006. The situation of tuberculosis and tuberculosis control in animals of economic interest. Tuberculosis, 86: 330335.

Aranaz, A., Cousins, D., Mateos, A. and Dominiguez, L. 2003. Elevation of Mycobacterium tuberculosis subsp. caprae Aranaz et al. 1999 to species rank as Mycobacterium caprae comb. nov., sp. nov. International Journal of Systemic and Evolutionary Microbiology, 53: $1785-1789$.

Auda, F. 2011. Seasonality of Tuberculosis. Journal of Global and Infectious Diseases, 3(1): $46-55$.

Awosile, B., Awoyomi, O. and Kehinde, O. 2012. Prevalence and Economic loss of Bovine Tuberculosis in a Municipal abattoir, Abeokuta South, Western Nigeria. .Journal of Animal Production, 40(2): 216-222.

Ayanwale, F. O. 1984. Studies on epidemiology of bovine tuberculosis in some states in southern Nigeria. Ph.D thesis University of Ibadan, Nigeria.

Brosch, R., Gordon, S., Marmiesse, M., Brodin, P., Buchrieser, C., Eiglmeier, K. 2002. A new evolutionary scenario for the Mycobacterium tuberculosis complex.Proceedings of National. Academic Science. USA., 99: 3684-3689.

Cadmus, S. and Adesokan, H. 2010. Bovine fetal wastage in Southwestern Nigeria: A survey of some abattoirs. Tropical Animal Health and Production, 42 ( 4 ): $617-621$ d o i : 10.1007/s11250-009-9465-x

Cadmus, S., Yakubu, M. and Magaji, A. 2010. Mycobacterium bovis, but also $M$ africanum present in raw milk of pastoral cattle in northcentral Nigeria. Tropical Animal Health and Production, 42: 10471048.

Cadmus, S., Palmer, S., Melissa, O., James, D. and Karen, G. 2006. Molecular Analysis of Human and Bovine Tubercle Bacilli from a Local Setting in Nigeria. Journal of Clinical Microbiology, 44: 29-34.

Cadmus S., Atsanda, N., Oni, S. and Akang, E. 2004. Bovine tuberculosis in one cattle herd in Ibadan in Nigeria. Veterinary Medicine Czech, 49; 409-412.

Cousins D. 2001. Mycobacterium bovis infection and control in domestic livestock. Review of scientific techniques (International Office of Epizootics) [Internet]. Feb; 20 (1):71-85. Available from: http://www.ncbi.nlm.nih.gov/pubm ed/11288521

De Lisle, G., Mackintosh, C. and Bengis, R. 2001. Mycobacterium bovis in free-living and captive wildlife, including farmed deer. Scientific and Technical Review, Office of International Epizootics, 20, 86-111.

Ejeh, E., Adeshokan, H., Raji, M., Bello, M., Musa, J., Kudi, A., Cadmus, S. 2014. Current status of Bovine Tuberculosis in Otukpo, Nigeria. Journal of Animal Production and Advances, 4(8): 501-507

Idigbe, E., Anyiwo, C. and Onwujekwe, D. 1986. Human pulmonary infection with bovine and atypical Mycobacterium in Lagos, Nigeria. Journal of Tropical Medicine and 
Hygiene, 89:143-148.

Jenkins, A., Cadmus, S., Venter, E., Pourcel, C., Haure, Y., Vergnaud, C. and Godfroid, J. 2011. Molecular epidemiology of human and animal tuberculosis in Ibadan, Southwestern Nigeria. Veterinary Microbiology, 151: 139-147.

Kubica, T., Agzamova, R., Wright, A., Rakishev, G., Rusch-Gerdes, S., $\mathrm{N}$ i e m a n n, S . 20006 . Mycobacterium bovis isolates with M. tuberculosis specific characteristics. Emerging and Infectious Diseases, 12: 763-765.

Kwaghe, A. V., Vakuru, C.T., Iwar, V. N., Ndahi, D. M., Abubakar, A. and Eze, E. 2015. Bovine tuberculosis: effects andchallenges faced by developed anddeveloping countries in the eradication process. CAB Reviews. 10(036):120.

Marais, B., Brittle, W., Painczyk, K., Hesseling, A., Beyers, N., Wasserman, E., Van soolingen, D. Warren, R. 2008. Use of lightemitting diode fluorescence microscopy to detect acid-fast bacilli in sputum. Clinical and Infectious Diseases, 47( 2): 203 2

$$
0
$$$$
7
$$

http://dx.doi.org/10.1086/589248. PMid:18532893.

Morello, Josephine A., Paul A. Granato, Marion E. Wilson, and Verna Morton 2006. Laboratory Manual and Workbook in Microbiology: Applications to Patient Car. 10th ed. Boston: McGraw-Hill Higher Education.

Muh a m m ad, B ., Haruna, I ., Abdulsamad, A. and Bichi, J. 2009. Foetal wastage in Northern Nigerian: The case of Gombe abattoir, Gombe State. Proceedings of the 13th Annual Conference of Animal Science (ACAS '08) ABU, Zaria, 13:124-127

Nair, M. G., Kumar, R., Lakkawar, A. W. and Varshney, K. C. 2006. A slaughterhouse and necropsy based study of lesions inbovines. Indian Veterinary Journa, 83 (5): 490-493.

Newton, S., Brent, A., Anderson, S., Whittaker, E. and Kampmann, B. 2008. Paediatric tuberculosis Lancet Infectious Diseases, 8 (8): 498-510.

Nwakpu, P. and Osakwe, I. 2007. Trends in volume and magnitude of foetal waste of slaughter Animals (2000-2005) in Ebonyi State of Nigeria. Research Journal of Animal Sciences, 1(1):30-35.

Nwanta, J., Umeononigwe, C., Abonyi, G. and Onunkwo, J. 2011 . Retrospective study of bovine and human tuberculosis in abattoirs and hospitals in Enugu State, Southeast, Nigeria. Journal of Public Health and Epidemiology, 3(7): 329-336.

Nwakpu, P. and Osakwe, I. 2007. Trends in volume and magnitude of foetal waste of slaughter Animals (2000-2005) in Ebonyi State of Nigeria. Research Journal of Animal Sciences, 1(1):30-35.

OIE Bovine TB World Organisation for Animal Health (OIE) 2009. Manual of Diagnostic Tests and Vaccines for Terrestrial Animals. Bovine tuberculosis adopted, May $\begin{array}{llll}2 & 0 & 0 & 9\end{array}$, http://www.oie.int/fileadmin/Home leng/Health_standards/tahm/2.04.0 7 Bovine TB.pdf

Olorunfemi, I. E. and Fasinmirin, J. T. 2011. Hydraulic Conductivity and Infiltration of Soils of Tropical Rain 
Forest Climate of Nigeria. Proceedings of the Environment Conference, Federal University of Agriculture, Abeokuta, Nigeria, Pp. 27-31.

Oluwafemi, R., Ilemobade, A. and Laseinde, E. 2001. Study of Tsetse fly and bovine trypanosomiasis in a Biological control of tsetse fly project area in Lafia Local Government of Nasarawa state, Nigeria. An unpublished Masters Degree Thesis Report, Federal University of Technology, Akure, Ondo state, July 2001. 165pp.

Omogbai, B. 2010. Rain days and their productivity in South-western Region of Nigeria. Journal of Human Ecology, 31(3): 185-195.

Prodinger, W., Brandstatter, A., Naumann, L., Pacciarini, M., Kubica, T., Boschiroli, M., Aranaz,A., Nagy, G., Cvetnic, Z., Ocepek, M., Skrypnyk, A., Erler, W., Niemann, S., Pavlik, I. and Moser, I. 2005. Characterization of Mycobacterium caprae isolates from Europe by mycobacterial interspersed repetitive unit genotyping. Journal of Clinical Microbiology, 43: 4984-4992.

Prodinger, W., Brandstatter, A., Naumann, L., Pacciarini, M., Kubica, T., Boschiroli, M., Aranaz, A., Nagy G., Cvetnic Z., Ocepek M., Skrypnyk A., Erler W., Niemann S., Pavlik I. and Moser, I. 2005. Characterization of Mycobacterium caprae isolates from Europe by mycobacterial interspersed repetitive unit genotyping. Journal of Clinical Microbiology, 43: 4984-4992.

Robert, W. B. 2009. "Microbiology with Diseases by Body System",
Pearson Education, Inc. Pp. 23-44.

Sam, A., James, M. and Stanley W. 2011. Bovine tuberculosis: A review of diagnostic tests for Mycobacterium bovis infection in cattle, $\mathrm{pp} 8$.

Sanusi, M., Abubakar, M. and Luka, B. 2006. Incidence of foetal wastage in ruminant animals slaughtered at Bauchi and Jos abattoirs. Proc.31st Ann. Conf. Nig. Soc. Anim. Prod. March 12-15. Bayero University, Kano, Nigeria. 31:102-106.

Shehu, L. M. 1988. A survey of tuberculosis and tubercle bacilli in Fulani herds, Nono and some herdsmen in Zaria, Nigeria M.sc Thesis, Ahmadu Bello University, Zaria.

Shitaye, J., Tsegaye, W. and Pavlik, I. 2007. Bovine tuberculosis infection in animals and human population in Ethiopia: A review. Veterinary Medicine, 52:317-332.

Smith, N., Gordon, S., de la RuaDomenech, R., Clifton-Hadley, R. S. and Hewinson, R. G. 2006. Bottlenecks and broomsticks: the molecular evolution of Mycobacterium bovis. National Review in Microbiology, 4(9):67081. Review PubMed PMID: 16912712.

Wilkins, M. J., Meyerson, J., Bartlett, P. C., Spieldenner, S. L., Berry, D. E., Mosher, L. B., Kaneene, J. B., Robonson-Dunn, B., Stobierski, M. G. and Boulton, M. L. 2008. Human Mycobacterium bovis infection and bovine tuberculosis outbreak, Michigan; 1994-2007; Emerging and Infectious Diseases, 14(4): 657-660.

Received: 10 ${ }^{\text {th }}$ August, 2017

Accepted: $1^{\text {st }}$ December, 2017 